\title{
Does Methylphenidate Work in Children and Adolescents with Attention Deficit Hyperactivity Disorder?
}

\author{
Johanne Pereira Ribeiro ${ }^{1}$, Emma Jasmine Arthur ${ }^{1}$, Christian Gluud ${ }^{2,3}$, Erik Simonsen ${ }^{1,4}$ \\ and Ole Jakob Storebø $1,5,6, *$ (D) \\ 1 Center for Evidence-Based Psychiatry, Psychiatric Research Unit, Psychiatry Region Zealand, \\ 4200 Slagelse, Denmark; joper@regionsjaelland.dk (J.P.R.); emma.jaa.live.no@gmail.com (E.J.A.); \\ es@regionsjaelland.dk (E.S.) \\ 2 Department of Regional Health Research, Faculty of Health Sciences, University of Southern Denmark, \\ 5000 Odense, Denmark; cgluud@ctu.dk \\ 3 The Copenhagen Trial Unit, Centre for Clinical Intervention Research, The Capital Region, \\ Copenhagen University Hospital, Rigshospitalet, 2100 Copenhagen, Denmark \\ 4 Department of Clinical Medicine, University of Copenhagen, 2100 Copenhagen, Denmark \\ 5 Department of Child and Adolescent Psychiatry, Psychiatry Region Zealand, 4000 Roskilde, Denmark \\ 6 Department of Psychology, University of Southern Denmark, 5000 Odense, Denmark \\ * Correspondence: ojst@regionsjaelland.dk
}

Citation: Pereira Ribeiro, J.; Arthur, E.J.; Gluud, C.; Simonsen, E.; Storebø, O.J. Does Methylphenidate Work in Children and Adolescents with Attention Deficit Hyperactivity Disorder? Pediatr. Rep. 2021, 13, 434-443. https://doi.org/10.3390/ pediatric 13030050

Academic Editor: Marco Carotenuto

Received: 1 July 2021

Accepted: 29 July 2021

Published: 1 August 2021

Publisher's Note: MDPI stays neutral with regard to jurisdictional claims in published maps and institutional affiliations.

Copyright: (c) 2021 by the authors. Licensee MDPI, Basel, Switzerland. This article is an open access article distributed under the terms and conditions of the Creative Commons Attribution (CC BY) license (https:/ / creativecommons.org/licenses/by/ $4.0 /)$.

\begin{abstract}
Objective: Attention deficit hyperactivity disorder (ADHD) is a common psychiatric disorder diagnosed in increasing proportions of children and adolescents. The psychostimulant methylphenidate has been considered the first-line pharmacological treatment for children and adolescents with ADHD for more than 60 years. Considering recent publications on methylphenidate for ADHD, we here give an overview of its effects in children and adolescents with ADHD, elicited by a well-disputed Cochrane review and narratively synthesise the evidence in the field. Method: We searched for systematic reviews and meta-analyses that investigated methylphenidate as an intervention for children and adolescence with ADHD compared with placebo or no treatment. We assessed the quality of the evidence using AMSTAR II. Results: We found 24 eligible systematic reviews and meta-analyses of which 11 were rated as high- quality evidence according to AMSTAR II. The evidence claiming that methylphenidate is beneficial in treating children and adolescents with ADHD was of very low certainty. The underreporting of adverse events in randomised clinical trials may impede an adequate depiction of the balance between benefits and harms. Conclusions: It appears that there is uncertain evidence on group-level to support the claim that methylphenidate is beneficial in treating children and adolescents with ADHD. Future randomised clinical trials and systematic reviews should include individual participant data, which would allow us to assess intervention effects across modifiers, like age, sex, ADHD subtypes, comorbidities, and dose.
\end{abstract}

Keywords: ADHD; attention deficit hyperactivity disorder; methylphenidate; stimulants; children; adolescents

\section{Introduction}

The attention deficit hyperactivity disorder (ADHD) diagnosis is based on persistent impairment of one or more of the following core symptoms: excessive inattention, hyperactivity, and impulsivity. Furthermore, symptoms must interfere with everyday life before the age of 7 years (ICD-10) or 12 years (DSM-5) [1,2]. Children and adolescents with ADHD are at increased risk of a broad spectrum of co-occurring conditions [3,4]. The disorder is diagnosed in increasing proportions of children and adolescents, which brings focus to the central nervous stimulant methylphenidate. This drug has been considered the first-line pharmacological treatment for children and adolescents with ADHD for more than 60 years [5]. 
The 2015 Cochrane review by Storebø and colleagues investigated the beneficial and harmful effects of methylphenidate as treatment for children and adolescents with ADHD [6,7]. Storebø and colleagues included 185 randomised clinical trials and found small potential beneficial effects of methylphenidate versus placebo or no-intervention. However, they noted that there are mutable, methodological flaws, such as lack of blinding and outcome reporting bias in the included trials, which prevented a clear estimation on the magnitude of intervention effects [6,7]. Storebø and colleagues found that methylphenidate may improve teacher-rated ADHD symptoms (standardised mean difference (SMD) -0.77 , $95 \%$ confidence interval (CI) -0.90 to $-0.64 ; 19$ trials, 1698 participants). The evidence was rated as very low-quality evidence due to risk of bias and heterogeneity. Teacher-rated general behaviour seemed to improve with methylphenidate (SMD $-0.87,95 \% \mathrm{CI}-1.04$ to $-0.71 ; 5$ trials, 668 participants). The evidence was rated as very low-quality evidence due to risk of bias and indirectness.

There was a small beneficial effect of methylphenidate on quality of life (SMD 0.61, $95 \%$ CI 0.42 to $0.80,3$ trials, 514 participants). The evidence was rated as of very low-quality due to high risk of bias, indirectness, and selective outcome reporting [7].

Methylphenidate significantly increased adverse events considered non-serious and the risks of serious adverse events could not be assessed due to lack of data [7]. This review was heavily criticised in articles and editorials [8-13]. The criticism was focused on erratic inclusion of studies, risk of bias assessment, and assessment of the quality of included studies and meta-analyses as well as errors in the data. The criticism was rebutted and it was shown that the evidence base for the use of methylphenidate in children and adolescents is in fact flawed [14-19]. None of the critical comments that led to amendments changed anything major in the results or conclusions. This viewpoint provides an overview of the evidence since the 2015 Cochrane review by Storebø and colleagues [6,7]. In this article, we consider the effects of methylphenidate in children and adolescents with ADHD and comorbid disorders compared with placebo or no-interventions.

\section{What New Publications Are out There?}

We searched PubMed, the Cochrane Library, and BMJ Best Practice on 6 October 2020, and achieved 477 full text hits after removing duplicates and irrelevant publications. Two independent reviewers went through titles and abstracts of these and excluded 449 studies, leaving 24 included studies. A third reviewer resolved disagreements. In cases where any author of this article was also co-author in an included review, we excluded that co-author from the assessment process. We included 24 reviews or meta-analyses in English, published in 2013 and onwards that investigated methylphenidate as an intervention for children and adolescence with ADHD compared with placebo or no treatment. Reviews investigating multiple interventions were included if data on methylphenidate was reported separately and it was possible to differentiate from other interventions. Two reviewers using the AMSTAR II checklist assessed the 24 included studies [20]. Of these, 11 reviews were of high quality (see Table 1) [21-31]. The remaining studies albeit relevant and fulfilling inclusion criteria had some concerns that affected the overall certainty of evidence. Some had not published a protocol prior to their study [32-38], had no comprehensive literature search $[33,35,39]$, were unclear on whether study inclusion and data extraction were performed in duplicates [33,40], had not conducted a thorough quality assessment $[32,34,35,38,41,42]$, had no report on risk of bias assessment of included studies [33-35,38,40-44], or had a combination of two or more of these caveats. 
Table 1. Quality assessment of included studies.

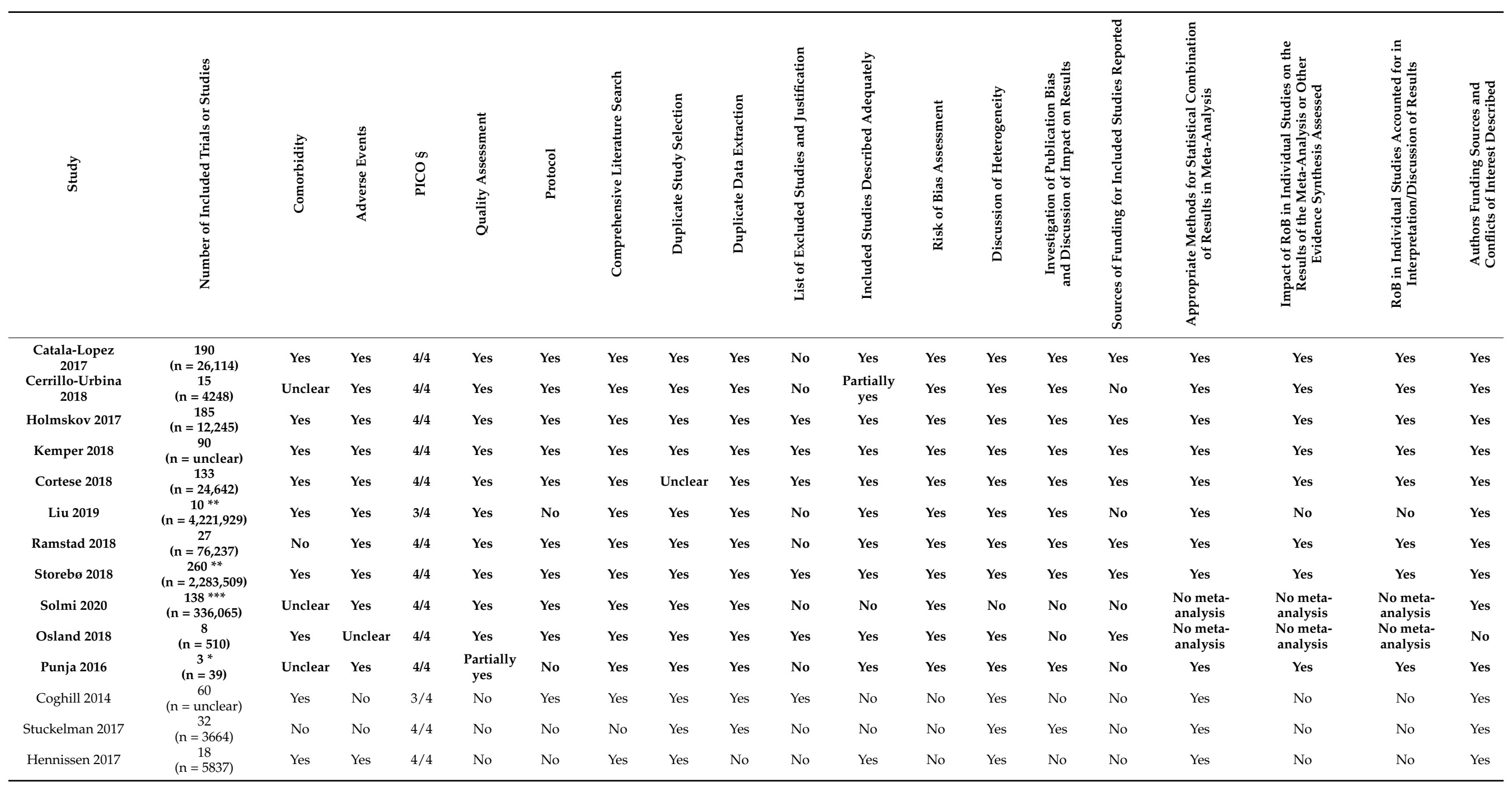


Table 1. Cont

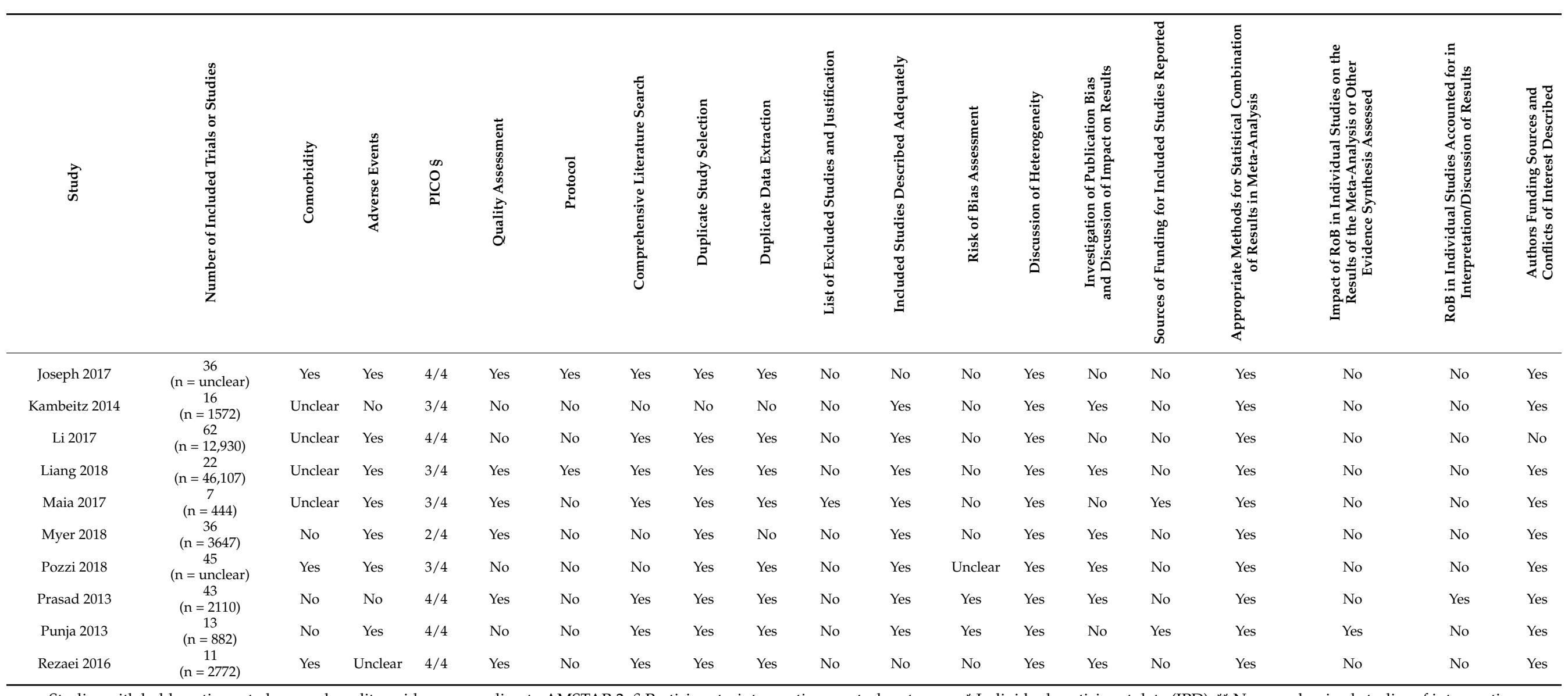

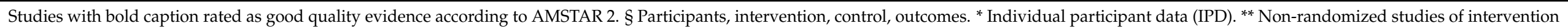
effects (NRSI). ${ }^{* * *}$ Combined randomized clinical trials and NRSI. 


\section{Assessment of Methylphenidate by Expert Groups}

The updated 2018 guideline from the National Institute for Health and Care Excellence (NICE) recommends methylphenidate as the first-line pharmacological treatment for children over 5 and adolescents [45]. There are several methodological problems with the NICE guideline on ADHD, regarding erratic assessment of the certainty of the included studies and selection bias as the authors only included 16 trials on methylphenidate in children and adolescents [46]. These limitations in the NICE guideline raises concerns about the validity of the recommendations.

Two researchers from Mount Sinai Graduate Program in Public Health applied for inclusion of methylphenidate on the WHO Model List of Essential Medicines in December 2018 for children, adolescents, and adults with ADHD [47]. The WHO Expert Committees rejected the application due to concerns regarding the quality and interpretation of the evidence for benefits and harms [48,49]. The decision was unanimous [48,49].

\section{How Efficient Is Methylphenidate in Recent Reviews or Meta-Analyses?}

Using individual participant data from 39 patients in n-of 1-trials in their meta-analysis, Punja and colleagues. (2016) concluded methylphenidate to be effective for ADHD in children [28]. The generalisability of the results however, may be limited as data from only one study contributed to most of the analyses. Catala-Lopez and colleagues (2017) included 40 trials on methylphenidate containing 3836 participants [21]. Catala-Lopez and colleagues deemed methylphenidate an efficient treatment for ADHD symptoms especially when combined with behavioural therapy. This conclusion was made with low to very low certainty in the evidence [21].

Utilising methylphenidate as the pharmacological first choice of treatment for children and adolescents with ADHD was supported in a large systematic review and network meta-analysis by Cortese and colleagues (2018), who compared efficacy and tolerability of methylphenidate for ADHD to placebo alongside other medications [23]. The authors however excluded many relevant trials to fulfil statistical and methodological assumptions in the network meta-analyses and thereby increased the risk of selection bias [50]. They did this because they believed that including these trials would have been a clear violation to their published protocol and also that this would have compromised the transitivity of the network meta-analyses [51]. Furthermore, the authors assessed all the indirect comparisons at low to very low quality of evidence. Indirect evidence differentiates network metaanalyses from conventional meta-analyses, and given the decreased interpretability of these data, the overall findings might not be more comprehensive or novel than previous reviews.

In an efficacy and safety assessment of stimulants and non-stimulants on ADHD symptoms for children and adolescents, Cerrillo-Urbina and colleagues (2018) concluded that both treatments alleviate ADHD symptoms and that stimulants especially seemed to have a superior effect on inattention and hyperactivity. Their review included only four trials on methylphenidate which were all conducted before 2013 and therefore did not encompass any new evidence [22].

Incorporating comorbidity in an effect analysis, a Cochrane review by Osland and colleagues (2018) investigated the effects of various pharmacological treatments, including methylphenidate for ADHD in children with comorbid tic disorder [27]. They found improvements of symptoms of ADHD and tics using methylphenidate based on lowcertainty evidence.

\section{What Are the Harms of Methylphenidate?}

When assessing the effects of methylphenidate, importance should be given to the balance between benefits as well as adverse effects.

Adverse effects of methylphenidate commonly investigated and reported include inter alia insomnia, anxiety, growth suppression, reduced weight gain and gastrointestinal events 
like nausea, abdominal pain, and reduced appetite [7]. Osland and colleagues. found that methylphenidate was associated with appetite suppression, weight loss, and insomnia [27].

The 2018 Cochrane systematic review of non-randomised studies on methylphenidate and adverse events in children and adolescents with ADHD by Storebø and colleagues, showed that methylphenidate may be associated with a number of serious adverse events as well as a large number of non-serious adverse events in children and adolescents, which often lead to withdrawal of methylphenidate [31]. The certainty in the evidence was very low, and accordingly, it was not possible to accurately estimate the risk of adverse events [31], which is likely higher than reported [31,52,53]. The 2015 Cochrane review by Storebø and colleagues [7] associated the use of short-term methylphenidate for ADHD in children and adolescents with a risk increase of appetite decline, weight loss, and abdominal pain [24]. Adverse effects require close monitoring, while clinical experiences suggest that most non-serious adverse effects disappear within a couple of weeks. Further, Storebø and colleagues [7] investigated the occurrence of psychotic symptoms in children and adolescents with ADHD receiving methylphenidate [29]. It was not possible to conclude on this matter due to low quality evidence and sparse data from an otherwise rigorous and exhaustive gathering of evidence [29].

When comparing treatment with methylphenidate to non-pharmacologic interventions, Kemper and colleagues found that methylphenidate increased sleep disturbance and decreased appetite. All but two included studies, however, were rated as having insufficient certainty of evidence by the authors, for which reason they decided that no other outcomes could be investigated [25].

Other serious adverse events of methylphenidate treatment for children and adolescents include the development of psychosis and cardiovascular problems. Investigating cardiovascular risks of methylphenidate and other pharmacological treatments for ADHD, Liu and colleagues could not exclude a modest elevated risk for sudden cardiac arrest and arrhythmia linked to the use of methylphenidate, based on confidence intervals. They advised that this risk be considered against the benefits of medication and suggested regular monitoring of heart rate and blood pressure [26].

\section{Balance between Benefits and Harms}

The underreporting of adverse events in randomised clinical trials may impede an adequate depiction of the balance between methylphenidate benefits and harms in children and adolescents with ADHD. The issue of underreporting adverse events is well known and has been investigated repeatedly $[54,55]$. In a recent umbrella review, Solmi and colleagues investigated adverse effects of pharmacological treatments for ADHD in children and adolescents [30]. According to Solmi and colleagues, only 32.1 percent of the literature on methylphenidate (which was the highest coverage in the group of ADHD medications) covered adverse events. In this group, only 6.4 percent found these to be significantly worse with methylphenidate compared to placebo. They found that participants in the methylphenidate group were much more likely to experience insomnia compared with participants in the placebo group (odds ratio: 4.7; 95\% CI 1.9-10.9). They also found an increased relative risk of gastrointestinal adverse events: abdominal pain (relative risk (RR) 1.5; 95\% CI 1.3-1.8), anorexia (RR 3.2; 95\% CI 2.6-3.9), and nausea/vomiting (RR 1.4; 95\% CI 1.0-1.8). Additionally, the standardised mean difference for weight loss was -0.77 with $95 \%$ CI -1.1 to -0.5 , in the methylphenidate group compared with the placebo group [30].

None of the included reviews of good quality from our search mentioned the effects of withdrawal symptoms. It is important to investigate collateral cognitive and emotional withdrawal effects such as s depression, poor concentration, agitation, irritability, and anxiety [56].

Consequently, when comparing benefits and harms it seems there are substantial risks of harms, which may have been overlooked in previous publications [57]. Against these risks, one has to evaluate the benefits. Very low certainty evidence suggests limited benefits of methylphenidate based on aggregate data [7,21-23,27]. Furthermore, the benefits of 
methylphenidate are solely assessed in trials with less than a 3-month duration [7,23]. We lack evidence supporting long-term treatments, as is the usual way of using the medication $[7,23]$.

We cannot of course ignore that some patients and clinicians experience advantages of methylphenidate. When looking at the evidence from clinical trials, the variance of the outcomes in the methylphenidate group does not seem to be larger than that of the placebo or no-intervention group. This makes it unclear whether there might be a differential effect between the groups [58]. Additionally, it is worth mentioning that the case is quite similar if we assess the effects of methylphenidate in adults with ADHD. That is, likely more harms than benefits. A new network meta-analysis investigating the benefits and harms of pharmacological treatment for adults showed possible beneficial effect of methylphenidate compared with placebo, however, certainty of the evidence was low to very low and there was limited reporting on long-term adverse events [59]. Recent systematic reviews question the effects of methylphenidate for adults with ADHD [59-61].

\section{Whom to Treat?}

Many experienced clinicians and researchers find that methylphenidate gives symptom reduction in some children and adolescents with ADHD, albeit the proportion of this group is unclear. Although the average treatment effect may not be above the clinically significant level, beneficial effects in one or more subgroups can occur. One way to identify such subgroups is to conduct individual patient data (IPD) reviews. In this type of review it is possible to look for information on whether patient characteristics influence treatment outcomes [62]. Moreover, potential symptom reduction in undefined subgroups should always be weighed against both serious and non-serious adverse events. The true number of adverse events remains uncertain given the insufficient quality of evidence and poor documentation of harms. Therefore, methylphenidate might potentially cause more harm for children and adolescents with ADHD than our studies indicate [17]. Swanepoel and colleagues published an article that focused on evolutionary thinking and how it can help to understand ADHD [63]. They argued that some children with ADHD struggle with the expectations in school to do sedentary work and concentrate for hours. This environment may, for some children, be the reason for their inattention and hyperactivity symptoms. This may be accommodated by a change in the environment, e.g., more physical activity in school [63] and potentially mindfulness-based therapies [64]. For the children where clinicians decide that medication is necessary, it may be important to evaluate benefits and harms with a systematic approach. Such an approach could take into account comorbidities, cardiovascular irregularities, sleeping and eating patterns, genetic heredity, and other risk factors. Potential benefits and harms should be discussed with patients and their caregivers [17]. An appropriate monitoring system that closely assesses the treatment benefits and harms over time should be used [17]. Careful titration is required to determine optimal dose and length of treatment. Medication should be discontinued if no improvement has occurred and a structured treatment-interruption should be considered due to unclear evidence and risk of harmful effects.

\section{Conclusions}

It appears that there may still be uncertain evidence on group-level to support the conclusion that methylphenidate would be beneficial in treating children and adolescents with ADHD. Future randomised clinical trials and systematic reviews should include individual participant data, which would allow us to assess intervention effects across modifiers, like age, sex, ADHD subtypes, comorbidities, and dose. These data must be present for both the short- and long-term effects of methylphenidate for children and adolescents. Only then, can we discover the subgroups of patients with ADHD that benefit the most from methylphenidate, as well as those that benefit the least.

Author Contributions: C.G. and O.J.S. developed the idea for the analysis; J.P.R. and E.J.A. screened abstracts and full texts, and conducted quality assessments of full articles; J.P.R. drafted the first ver- 
sion of the manuscript and created the supplementary table; C.G., E.S., and O.J.S. critically reviewed and revised the manuscript; O.J.S. contributed with added sections to the original manuscript and resolved disagreements in the literature search; O.J.S. is the guarantor of this article. All authors have read and agreed to the published version of the manuscript.

Funding: This work was not supported by any external funding.

Acknowledgments: We thank Trine Kæstel for her support with the literature search.

Conflicts of Interest: The authors declare that the research was conducted in the absence of any commercial or financial relationships that could be construed as a potential conflict of interest.

\section{References}

1. American Psychiatric Association. Diagnostic and Statistical Manual of Mental Disorders (DSM-5 $\left.{ }^{\circledR}\right)$; American Psychiatric Association: Arlington, VA, USA, 2013.

2. World Health Organization. The ICD-10 Classification of Mental and Behavioural Disorders: Clinical Descriptions and Diagnostic Guidelines; World Health Organization: Geneva, Switzerland, 1992; Volume 1.

3. Faraone, S.V.; Asherson, P.; Banaschewski, T.; Biederman, J.; Buitelaar, J.K.; Ramos-Quiroga, J.A.; Rohde, L.A.; Sonuga-Barke, E.J.S.; Tannock, R.; Franke, B. Attention-deficit/hyperactivity disorder. Nat. Rev. Dis. Prim. 2015, 1, 15020. [CrossRef] [PubMed]

4. Schmidt, S.; Petermann, F. Developmental psychopathology: Attention Deficit Hyperactivity Disorder (ADHD). BMC Psychiatry 2009, 9, 58. [CrossRef] [PubMed]

5. Gadoth, N. Methylphenidate (Ritalin): What Makes it so Widely Prescribed during the Last 60 Years? Curr. Drug Ther. 2014, 8 , 171-180. [CrossRef]

6. Storebø, O.J.; Krogh, H.B.; Ramstad, E.; Moreira-Maia, C.R.; Holmskov, M.; Skoog, M.; Nilausen, T.D.; Magnusson, F.L.; Zwi, M.; Gillies, D.; et al. Methylphenidate for attention-deficit/hyperactivity disorder in children and adolescents: Cochrane systematic review with meta-analyses and trial sequential analyses of randomised clinical trials. BMJ 2015, 351, h5203. [CrossRef] [PubMed]

7. Storebø, O.J.; Ramstad, E.; Krogh, H.B.; Nilausen, T.D.; Skoog, M.; Holmskov, M.; Rosendal, S.; Groth, C.; Magnusson, F.L.; Moreira-Maia, C.R.; et al. Methylphenidate for children and adolescents with attention deficit hyperactivity disorder (ADHD). Cochrane Database Syst. Rev. 2015, CD009885. [CrossRef] [PubMed]

8. Banaschewski, T.; Buitelaar, J.; Chui, C.S.L.; Coghill, D.; Cortese, S.; Simonoff, E.; Wong, I.C.K. Methylphenidate for ADHD in children and adolescents: Throwing the baby out with the bathwater. Évid. Based Ment. Health 2016, 19, 97-99. [CrossRef]

9. Banaschewski, T.; Gerlach, M.; Becker, K.; Holtmann, M.; Döpfner, M.; Romanos, M. Trust, but verify. The errors and misinterpretations in the Cochrane analysis by O. J. Storebo and colleagues on the efficacy and safety of methylphenidate for the treatment of children and adolescents with ADHD. Z. Kinder Jugendpsychiatrie Psychother. 2016, 44, 307-314. [CrossRef]

10. Hollis, C.; Professor of Child \& Adolescent Psychiatry and Director, NIHR MindTech MIC, Faculty of Medicine \& Health Sciences. Methylphenidate for ADHD: Have Cochrane Got It Wrong This Time? Response to: Storebø, O.J.; Ramstad, E.; Krogh, H.B.; Nilausen, T.D.; Skoog, M.; Holmskov, M. Personal communication, 2016.

11. Hoekstra, P.J.; Buitelaar, J.K. Is the evidence base of methylphenidate for children and adolescents with attentiondeficit/hyperactivity disorder flawed? Eur. Child Adolesc. Psychiatry 2016, 25, 339-340. [CrossRef] [PubMed]

12. Romanos, M.; Reif, A.; Banaschewski, T. Methylphenidate for Attention-Deficit/Hyperactivity Disorder. JAMA 2016, 316, 994-995. [CrossRef] [PubMed]

13. Swanson, J.M. Risk of Bias and Quality of Evidence for Treatment of ADHD with Stimulant Medication. Clin. Pharmacol. Ther. 2018, 104, 638-643. [CrossRef]

14. Storebø, O.J.; Professor, Department of Psychology, University of Southern Denmark; Gluud, C.; Professor at Department of Regional Health Research, Faculty of Health Sciences, University of Southern Denmark. Response to Hollis C. Methylphenidate for ADHD: Have Cochrane Got It Wrong This Time? Personal communication, 2016.

15. Storebø, O.J.; Zwi, M.; Krogh, H.B.; Moreira-Maia, C.R.; Holmskov, M.; Gillies, D.; Groth, C.; Simonsen, E.; Gluud, C. Evidence on methylphenidate in children and adolescents with ADHD is in fact of 'very low quality'. Évid. Based Ment. Health 2016, 19, 100-102. [CrossRef]

16. Storebø, O.J.; Zwi, M.; Moreira-Maia, C.R.; Skoog, M.; Camilla, G.; Gillies, D.; Simonsen, E.; Gluud, C. Response to “Trust, but verify" by Banaschewski T.; Gerlach M.; Becker K.; Holtmann M.; Döpfner M.; Romanos M. Z. Kinder Jugendpsychiatrie Psychother. 2016, 44, 334-335. [CrossRef]

17. Storebø, O.J.; Faltinsen, E.; Zwi, M.; Simonsen, E.; Gluud, C. The Jury Is Still Out on the Benefits and Harms of Methylphenidate for Children and Adolescents with Attention-Deficit/Hyperactivity Disorder. Clin. Pharmacol. Ther. 2018, 104, 606-609. [CrossRef] [PubMed]

18. Storebø, O.J.; Simonsen, E.; Gluud, C. The evidence base of methylphenidate for children and adolescents with attention-deficit hyperactivity disorder is in fact flawed. Eur. Child Adolesc. Psychiatry 2016, 25, 1037-1038. [CrossRef]

19. Storebø, O.J.; Simonsen, E.; Gluud, C. Methylphenidate for Attention-Deficit/Hyperactivity Disorder-Reply. JAMA 2016, 316, 995. [CrossRef] [PubMed] 
20. Shea, B.J.; Reeves, B.C.; Wells, G.; Thuku, M.; Hamel, C.; Moran, J.; Moher, D.; Tugwell, P.; Welch, V.; Kristjansson, E.; et al. AMSTAR 2: A critical appraisal tool for systematic reviews that include randomised or non-randomised studies of healthcare interventions, or both. BMJ 2017, 358, j4008. [CrossRef] [PubMed]

21. Catalá-López, F.; Hutton, B.; Núñez-Beltrán, A.; Page, M.; Ridao, M.; Saint-Gerons, D.M.; Catalá, M.A.; Tabares-Seisdedos, R.; Moher, D. The pharmacological and non-pharmacological treatment of attention deficit hyperactivity disorder in children and adolescents: A systematic review with network meta-analyses of randomised trials. PLoS ONE 2017, 12, e0180355. [CrossRef] [PubMed]

22. Cerrillo-Urbina, A.J.; García-Hermoso, A.; Pardo-Guijarro, M.J.; López, M.S.; Santos-Gómez, J.L.; Martinez-Vizcaino, V. The Effects of Long-Acting Stimulant and Nonstimulant Medications in Children and Adolescents with Attention-Deficit/Hyperactivity Disorder: A Meta-Analysis of Randomized Controlled Trials. J. Child Adolesc. Psychopharmacol. 2018, 28, 494-507. [CrossRef]

23. Cortese, S.; Adamo, N.; Del Giovane, C.; Mohr-Jensen, C.; Hayes, A.J.; Carucci, S.; Atkinson, L.Z.; Tessari, L.; Banaschewski, T.; Coghill, D.; et al. Comparative efficacy and tolerability of medications for attention-deficit hyperactivity disorder in children, adolescents, and adults: A systematic review and network meta-analysis. Lancet Psychiatry 2018, 5, 727-738. [CrossRef]

24. Holmskov, M.; Storebø, O.J.; Moreira-Maia, C.R.; Ramstad, E.; Magnusson, F.L.; Krogh, H.B.; Groth, C.; Gillies, D.; Zwi, M.; Skoog, M.; et al. Gastrointestinal adverse events during methylphenidate treatment of children and adolescents with attention deficit hyperactivity disorder: A systematic review with meta-analysis and Trial Sequential Analysis of randomised clinical trials. PLoS ONE 2017, 12, e0178187. [CrossRef]

25. Kemper, A.R.; Maslow, G.R.; Hill, S.; Namdari, B.; LaPointe, N.M.A.; Goode, A.P.; Coeytaux, R.R.; Befus, D.; Kosinski, A.S.; Bowen, S.E.; et al. AHRQ Comparative Effectiveness Reviews. Available online: https:/ / www.ncbi.nlm.nih.gov/books/NBK487 $761 /$ (accessed on 30 July 2021).

26. Liu, H.; Feng, W.; Zhang, D. Association of ADHD medications with the risk of cardiovascular diseases: A meta-analysis. Eur. Child Adolesc. Psychiatry 2018, 28, 1283-1293. [CrossRef] [PubMed]

27. Osland, S.T.; Steeves, T.D.; Pringsheim, T. Pharmacological treatment for attention deficit hyperactivity disorder (ADHD) in children with comorbid tic disorders. Cochrane Database Syst. Rev. 2018, 6, CD007990. [CrossRef]

28. Punja, S.; Xu, D.; Schmid, C.; Hartling, L.; Urichuk, L.; Nikles, J.N.; Vohra, S. N-of-1 trials can be aggregated to generate group mean treatment effects: A systematic review and meta-analysis. J. Clin. Epidemiol. 2016, 76, 65-75. [CrossRef] [PubMed]

29. Ramstad, E.; Storebø, O.J.; Gerner, T.; Krogh, H.B.; Holmskov, M.; Magnusson, F.L.; Moreira-Maia, C.R.; Skoog, M.; Groth, C.; Gillies, D.; et al. Hallucinations and other psychotic symptoms in response to methylphenidate in children and adolescents with attention-deficit/hyperactivity disorder: A Cochrane systematic review with meta-analysis and trial sequential analysis\#. Scand. J. Child Adolesc. Psychiatry Psychol. 2018, 6, 52-71. [CrossRef]

30. Solmi, M.; Fornaro, M.; Ostinelli, E.G.; Zangani, C.; Croatto, G.; Monaco, F.; Krinitski, D.; Fusar-Poli, P.; Correll, C.U. Safety of 80 antidepressants, antipsychotics, anti-attention-deficit/hyperactivity medications and mood stabilizers in children and adolescents with psychiatric disorders: A large scale systematic meta-review of 78 adverse effects. World Psychiatry 2020, 19, 214-232. [CrossRef] [PubMed]

31. Storebø, O.J.; Pedersen, N.; Ramstad, E.; Kielsholm, M.L.; Nielsen, S.S.; Krogh, H.B.; Moreira-Maia, C.R.; Magnusson, F.L.; Holmskov, M.; Gerner, T.; et al. Methylphenidate for attention deficit hyperactivity disorder (ADHD) in children and adolescentsAssessment of adverse events in non-randomised studies. Cochrane Database Syst. Rev. 2018, 5, CD012069. [CrossRef]

32. Hennissen, L.; Bakker, M.J.; Banaschewski, T.; Carucci, S.; Coghill, D.; Danckaerts, M.; Dittmann, R.W.; Hollis, C.; Kovshoff, H. Cardiovascular Effects of Stimulant and Non-Stimulant Medication for Children and Adolescents with ADHD: A Systematic Review and Meta-Analysis of Trials of Methylphenidate, Amphetamines and Atomoxetine. CNS Drugs 2017, 31, 199-215. [CrossRef]

33. Kambeitz, J.; Romanos, M.; Ettinger, U. Meta-analysis of the association between dopamine transporter genotype and response to methylphenidate treatment in ADHD. Pharm. J. 2013, 14, 77-84. [CrossRef]

34. Li, Y.; Gao, J.; He, S.; Zhang, Y.; Wang, Q. An Evaluation on the Efficacy and Safety of Treatments for Attention Deficit Hyperactivity Disorder in Children and Adolescents: A Comparison of Multiple Treatments. Mol. Neurobiol. 2016, 54, 6655-6669. [CrossRef]

35. Pozzi, M.; Carnovale, C.; Peeters, G.G.; Gentili, M.; Antoniazzi, S.; Radice, S.; Clementi, E.; Nobile, M. Adverse drug events related to mood and emotion in paediatric patients treated for ADHD: A meta-analysis. J. Affect. Disord. 2018, 238, 161-178. [CrossRef] [PubMed]

36. Prasad, V.; Brogan, E.; Mulvaney, C.; Grainge, M.; Stanton, W.; Sayal, K. How effective are drug treatments for children with ADHD at improving on-task behaviour and academic achievement in the school classroom? A systematic review and meta-analysis. Eur. Child Adolesc. Psychiatry 2013, 22, 203-216. [CrossRef]

37. Rezaei, G.; Hosseini, S.A.; Sari, A.A.; Olyaeemanesh, A.; Lotfi, M.H.; Yassini, M.; Bidaki, R.; Nouri, B. Comparative efficacy of methylphenidate and atomoxetine in the treatment of attention deficit hyperactivity disorder in children and adolescents: A systematic review and meta-analysis. Med. J. Islam. Repub. Iran 2016, 30, 325.

38. Stuckelman, Z.D.; Mulqueen, J.M.; Ferracioli-Oda, E.; Cohen, S.C.; Coughlin, C.G.; Leckman, J.F.; Bloch, M.H. Risk of Irritability with Psychostimulant Treatment in Children With ADHD. J. Clin. Psychiatry 2017, 78, e648-e655. [CrossRef] [PubMed]

39. Myer, N.M.; Boland, J.R.; Faraone, S.V. Pharmacogenetics predictors of methylphenidate efficacy in childhood ADHD. Mol. Psychiatry 2017, 23, 1929-1936. [CrossRef] [PubMed] 
40. Joseph, A.; Ayyagari, R.; Xie, M.; Cai, S.; Xie, J.; Huss, M.; Sikirica, V. Comparative efficacy and safety of attentiondeficit/hyperactivity disorder pharmacotherapies, including guanfacine extended release: A mixed treatment comparison. Eur. Child Adolesc. Psychiatry 2017, 26, 875-897. [CrossRef] [PubMed]

41. Coghill, D.R.; Seth, S.; Pedroso, S.; Usala, T.; Currie, J.; Gagliano, A. Effects of Methylphenidate on Cognitive Functions in Children and Adolescents with Attention-Deficit/Hyperactivity Disorder: Evidence from a Systematic Review and a Meta-Analysis. Biol. Psychiatry 2014, 76, 603-615. [CrossRef] [PubMed]

42. Punja, S.; Zorzela, L.; Hartling, L.; Urichuk, L.; Vohra, S. Long-acting versus short-acting methylphenidate for paediatric ADHD: A systematic review and meta-analysis of comparative efficacy. BMJ Open 2013, 3, e002312. [CrossRef] [PubMed]

43. Liang, E.F.; Lim, S.Z.; Tam, W.W.; Ho, C.S.; Zhang, M.W.; McIntyre, R.S.; Ho, R.C. The Effect of Methylphenidate and Atomoxetine on Heart Rate and Systolic Blood Pressure in Young People and Adults with Attention-Deficit Hyperactivity Disorder (ADHD): Systematic Review, Meta-Analysis, and Meta-Regression. Int. J. Environ. Res. Public Health 2018, 15, 1789. [CrossRef]

44. Maia, C.R.M.; Cortese, S.; Caye, A.; Deakin, T.K.; Polanczyk, G.V.; Polanczyk, C.A.; Rohde, L.A.P. Long-Term Efficacy of Methylphenidate Immediate-Release for the Treatment of Childhood ADHD. J. Atten. Disord. 2016, 21, 3-13. [CrossRef]

45. National Institute for Health and Care Excellence. Clinical Guidelines. In Attention Deficit Hyperactivity Disorder: Diagnosis and Management; National Institute for Health and Care Excellence: London, UK, 2018.

46. Faltinsen, E.; Zwi, M.; Castells, X.; Gluud, C.; Simonsen, E.; Storebø, O.J. Updated 2018 NICE guideline on pharmacological treatments for people with ADHD: A critical look. BMJ Evid. Based Med. 2018, 24, 99-102. [CrossRef] [PubMed]

47. Moscibrodzki, P.K.C. Application for Inclusion to the 22nd Expert Committee on the Selection and Use of Essential Medicines: Methylphenidate Hydrchloride. Available online: https://www.who.int/medicines/publications/essentialmedicines/ UNEDITED_TRS_2019_EC22_Sept.pdf?ua=1 (accessed on 30 July 2021).

48. World Health Organization. The Selection and Use of Essential Medicines. The 21st WHO Model List of Essential Medicines and the 7th WHO Model List of Essential Medicines for Children. Section 24: Medicines for Mental and Behavioural Disorders. Methylphenidate-Addition-EML and EMLc. Available online: https://www.who.int/medicines/publications/ essentialmedicines/en/ (accessed on 30 July 2021).

49. Storebø, O.J.; Gluud, C. Methylphenidate for ADHD rejected from the WHO Essential Medicines List due to uncertainties in benefit-harm profile. BMJ Evid.-Based Med. 2021, 26, 172-175. [CrossRef] [PubMed]

50. Faltinsen, E.G.; Gluud, C.; Simonsen, E.; Zwi, M.; Storebø, O.J. Unbalanced risk-benefit analysis of ADHD drugs. Lancet Psychiatry 2018, 5, 870. [CrossRef]

51. Cipriani, A.; Adamo, N.; Del Giovane, C.; Coghill, D.; Banaschewski, T.; Hollis, C.; Zuddas, A.; Simonoff, E.; Cortese, S. Unbalanced risk-benefit analysis of ADHD drugs-Authors' reply. Lancet Psychiatry 2018, 5, 871-873. [CrossRef]

52. Ioannidis, J.P.; Contopoulos-Ioannidis, D.G. Reporting of safety data from randomised trials. Lancet 1998, 352, 1752-1753. [CrossRef]

53. Ioannidis, J.P. Adverse events in randomized trials: Neglected, restricted, distorted, and silenced. Arch. Intern. Med. 2009, 169, 1737-1739. [CrossRef] [PubMed]

54. Golder, S.; Loke, Y.K.; Wright, K.; Norman, G. Reporting of Adverse Events in Published and Unpublished Studies of Health Care Interventions: A Systematic Review. PLoS Med. 2016, 13, e1002127. [CrossRef]

55. Schroll, J.B.; Penninga, E.I.; Gøtzsche, P.C. Assessment of Adverse Events in Protocols, Clinical Study Reports, and Published Papers of Trials of Orlistat: A Document Analysis. PLoS Med. 2016, 13, e1002101. [CrossRef]

56. Department of Health. The Psychostimulant Withdrawal Syndrome. Available online: https://www1.health.gov.au/internet/ publications / publishing.nsf/Content/drugtreat-pubs-modpsy-toc \{\}drugtreat-pubs-modpsy-3 \{\}drugtreat-pubs-modpsy-37 \{\}drugtreat-pubs-modpsy-3-7-pws (accessed on 25 July 2021).

57. Graham, J.; Banaschewski, T.; Buitelaar, J.; Coghill, D.; Danckaerts, M.; Dittmann, R.; Döpfner, M.; Hamilton, R.; Hollis, C. European guidelines on managing adverse effects of medication for ADHD. Eur. Child Adolesc. Psychiatry 2011, $20,17-37$. [CrossRef] [PubMed]

58. Cortés, J.; González, J.A.; Medina, M.N.; Vogler, M.; Vilaró, M.; Elmore, M.; Senn, S.J.; Campbell, M.; Cobo, E. Does evidence support the high expectations placed in precision medicine? A bibliographic review. F1000 Res. 2018, 7. [CrossRef]

59. Elliott, J.; Johnston, A.; Husereau, D.; Kelly, S.E.; Eagles, C.; Charach, A.; Hsieh, S.-C.; Bai, Z.; Hossain, A.; Skidmore, B.; et al. Pharmacologic treatment of attention deficit hyperactivity disorder in adults: A systematic review and network meta-analysis. PLoS ONE 2020, 15, e0240584. [CrossRef] [PubMed]

60. Boesen, K.; Saiz, L.C.; Erviti, J.; Storebø, O.J.; Gluud, C.; Gøtzsche, P.C.; Jørgensen, K.J. The Cochrane Collaboration withdraws a review on methylphenidate for adults with attention deficit hyperactivity disorder. Evid. Based Med. 2017, 22, 143-147. [CrossRef]

61. Cândido, R.C.F.; Menezes de Padua, C.A.; Golder, S.; Junqueira, D.R. Immediate-release methylphenidate for attention deficit hyperactivity disorder (ADHD) in adults. Cochrane Database Syst. Rev. 2021, CD013011. [CrossRef]

62. Higgins, J.P.; Thomas, J.; Chandler, J.; Cumpston, M.; Li, T.; Page, M.J.; Welch, V.A. The Cochrane Handbook for Systematic Reviews of Interventions; John Wiley \& Sons: Hoboken, NJ, USA, 2019.

63. Swanepoel, A.; Music, G.; Launer, J.; Reiss, M. How evolutionary thinking can help us to understand ADHD. BJPsych Adv. 2017, 23, 410-418. [CrossRef]

64. Cairncross, M.; Miller, C.J. The Effectiveness of Mindfulness-Based Therapies for ADHD: A Meta-Analytic Review. J. Atten. Disord. 2016, 24, 627-643. [CrossRef] [PubMed] 